\title{
Use of navigation GPSs in small topographical surveying ${ }^{\dagger}$
}

\author{
Miguel Julio Machado Guimarães ${ }^{1, \star ~(D), ~ L u c a s ~ R a i m u n d o ~ D a ~ S i l v a ~ A r a u ́ j o ~}{ }^{1}$, Cristina Akemi Mogami ${ }^{2}$, \\ Fábio Dos Anjos Rezende ${ }^{2}$ and Italo Emanuel Dos Anjos Santos ${ }^{1}$ \\ 'Programa de Pós-Graduação em Engenharia Agrícola, Universidade Federal do Vale do São Francisco, Juazeiro, BA, Brazil., \\ and ${ }^{2}$ Instituto Federal de Educação, Ciência e Tecnologia do Sertão Pernambucano, Petrolina, PE, Brazil. \\ *Corresponding author: Email: mjmguimaraes@hotmail.com
}

(Received 02 May 2020; Revised 09 June 2020; Accepted 09 June 2020)

\begin{abstract}
In recent years the availability of geolocation data has increased considerably and can be found in various portable devices such as smartphones. These devices are intended for navigation in general, but can be used to carry out topographical surveys that do not require high accuracy of the surveyed data. To verify the applicability and accuracy of these devices we conducted the topographic survey in an area of approximately 5 ha using a GPS with RTK technology as reference, a Commercial Navigation Receiver (RNC) and a popular brand smartphone with the mobile applications C7 GPS Data and GPS Essentials previously installed. The GPS RNC showed the best planimetric results and the Smartphone with C7 GPS Data obtained the best result altimetric. None of the receivers analyzed showed high accuracy in results obtained. However, they can be used for tasks where high precision is not required.
\end{abstract}

Keywords: GNSS; Cartographic; Smartphone

\section{Introduction}

The more accurate the equipment used in topographical surveys, the better the representation of space will be. In recent years the need for geolocation data has increased considerably, so that this information has been improved and arranged in various electronics that are of daily use to people, such as smartphones that, due to constant evolutions, development and improvement of applications, have demonstrated unlimited options for work in the area of topography (Gonçalves \& Borges, 2016). The use of GPSs and smartphones for topographic surveys is mostly facilitated by their operational systems, but this use should be tested to ensure the accuracy of the data obtained (Yoon et al., 2016), since the use of equipment with these technologies without observing the technical characteristics as to the accuracy limit of each device can generate numerous errors and may even compromise the entire result of the work performed (Moreira et al., 2014).

\section{Objective}

The aim of this study was to verify the accuracy of topographic surveys performed with navigation receivers and Smartphone (planimetric and altitude survey).

\footnotetext{
${ }^{\dagger}$ The original article was published with a typographical error in the title. An erratum has been issued. 


\section{Methods}

The GPS RTK GNSS Receiver (X900) was used as a reference for comparative analysis of topographical survey performance, and the GPSmap 76CSx (RNC) receivers and a popular branded with Android 7.0 operating system and the C7 GPS Data and GPS Essentials mobile applications. To delimit the area, wooden pickets were allocated at 17 previously identified points, forming a closed polygonal in the study area. The coordinates obtained from the GPS RTK receiver were considered as reference positioning coordinates. The data were then collected with the GPS RNC, and with the smartphone with the applications. All receivers were configured to obtain UTM plane coordinates and SIRGAS2000 Horizontal Datum. With the data, the discrepancies between coordinates and the resulting discrepancy were determined, being: $\Delta \mathrm{E}=\mathrm{ET}-\mathrm{ER} ; \Delta \mathrm{N}=\mathrm{NT}-\mathrm{NR} ; \Delta \mathrm{H}=\mathrm{HT}-\mathrm{HR}$ and $\Delta \mathrm{d}=\sqrt{ } \Delta \mathrm{E}^{2}+\Delta \mathrm{N}^{2}$, where $\Delta \mathrm{E}$ are coordinate discrepancies East, $\Delta \mathrm{N}$ discrepancies of coordinates North, $\Delta \mathrm{d}$ resulting discrepancy, $\mathrm{T}$ are the coordinates to be tested and $\mathrm{R}$ are the reference coordinates.

\section{Results}

The results obtained indicate that the RNC presented results of $\Delta \mathrm{d}$ lower than those found by the other receivers, with about $1.73 \mathrm{~m}$. The Smartphone with C7 GPS Data showed similar results, with a $\Delta \mathrm{d}$ of 2.1 $\mathrm{m}$ (Table 1). When comparing the $\Delta \mathrm{H}$, the lowest error values were recorded at the points marked with the Smartphone with C7 GPS Data, with an average of $2.79 \mathrm{~m}$ (Table 2). A considerable difference between the coordinates recorded with the applications on the same smartphone can be observed. For the total area the biggest error was observed by the Smartphone with Essential GPS, with an underestimate of approximately $4 \%$ in the total area and $0.39 \%$ in the perimeter. The altimetric profiles made showed that there is a discrepancy between the profiles drawn by the RTK GPS and the other receivers (Fig. 1). However, the receivers evaluated showed a trend very close to the RTK GPS profile.

\section{Discussions}

The significant differences between the coordinates recorded with the applications in the same Smartphone indicate that their programming may have interfered in the collection of this data, since the surveys were conducted on the same day, time and place. The use of GPS navigation, including mobile applications, in small topographic surveys is feasible, since the errors (EA and EP) found, although considerable, did not exceed the margin of $5 \%$ considering the variation for more or less. The data

Table 1. Positioning discrepancies, in meters, of North UTM coordinates $(\Delta \mathrm{N})$, East $(\Delta \mathrm{E})$, geometric altitude $(\Delta \mathrm{H})$ and horizontal distance error $(\Delta \mathrm{d})$ of topographic surveys performed with GPS navigation.

\begin{tabular}{lllll}
\hline Receivers & $\Delta \mathrm{N}$ & $\Delta \mathrm{E}$ & $\Delta \mathrm{H}$ & $\Delta \mathrm{d}$ \\
\hline RNC & 0.88 & 1.39 & 6.52 & 1.73 \\
\hline Smartphone with C7 GPS Data & 0.86 & 1.78 & 2.79 & 2.10 \\
\hline Smartphone with GPS Essential & 1.53 & 3.55 & 9.17 & 4.14 \\
\hline
\end{tabular}

Table 2. Total area, perimeter and their respective errors $(\Delta \mathrm{A}$ and $\Delta \mathrm{P})$ of the surveys conducted with different receivers.

\begin{tabular}{lcccccc}
\hline Receiver & Area $\left(\mathrm{m}^{2}\right)$ & Perimeter $(\mathrm{m})$ & $\Delta \mathrm{A}$ & $\Delta \mathrm{P}$ & EA $(\%)$ & EP $(\%)$ \\
\hline RTK GPS & $53,484.35$ & $1,281.65$ & - & - & - & - \\
\hline RNC & $53,964.50$ & $1,282.03$ & 480.15 & 0.38 & 0.89 & 0.03 \\
\hline Smartphone with C7 GPS Data & $53,720.27$ & $1,276.87$ & 235.92 & -4.78 & 0.44 & -0.37 \\
\hline Smartphone with GPS Essential & $51,418.79$ & $1,276.67$ & -2.065 .56 & -4.98 & -4.02 & -0.39 \\
\hline
\end{tabular}




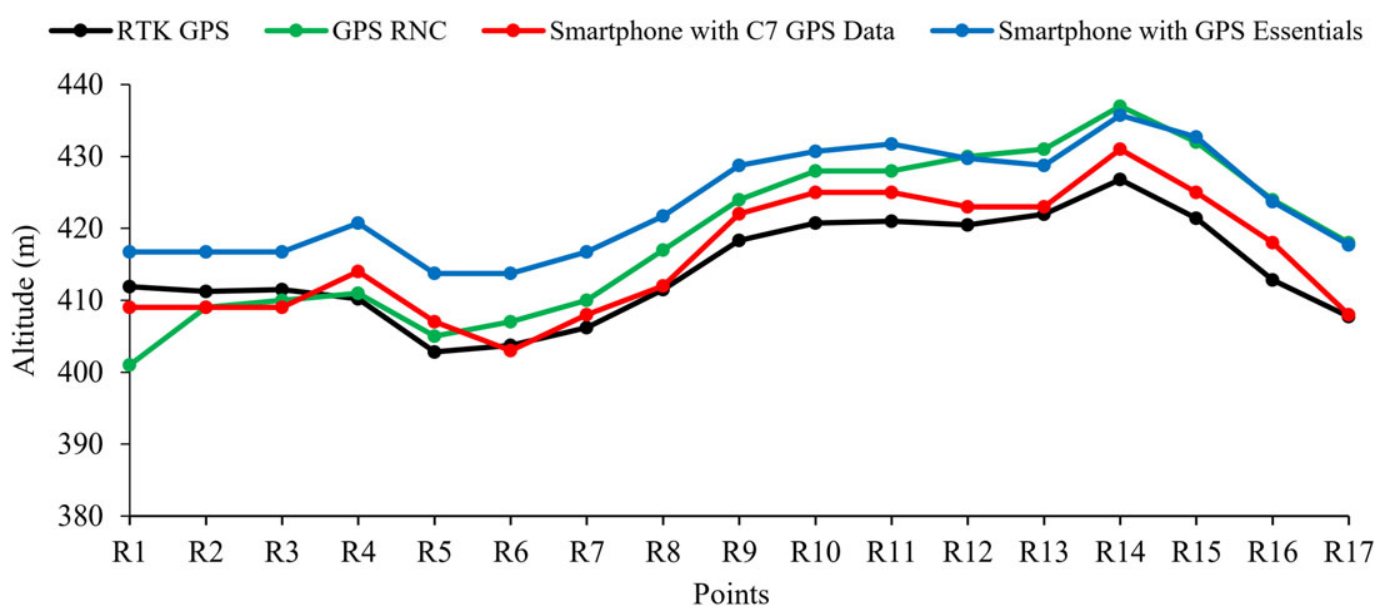

Figure 1. Altimetric profile performed with different receivers. RNC - Commercial Navigation Receiver.

obtained corroborates with Machado and Molin (2011) that registered EA under $3 \mathrm{~m}$ when evaluating various navigation GPSs, and Moreira et al. (2014) that recorded errors of less than $4 \mathrm{~m}$. Hwang et al. (2012) and Dabove and Pietra (2019) state that a viable alternative to reduce errors in topographic surveys conducted by navigation GPSs would be the development of applications capable of using Network Real-Time Kinematic (NRTK) GPS data technology in their surveys.

\section{Conclusions}

The GPS RNC showed the best planimetric results and the Smartphone with GPS Essential the worst result. For altimetry, the Smartphone with C7 GPS Data obtained the best result, and the worst being again the Smartphone with GPS Essential. None of the receivers analyzed showed satisfactory results for jobs requiring high accuracy. However, they can be used for tasks where high precision is not required.

Acknowledgements. The authors would like to thank Instituto Federal de Educação, Ciência e Tecnologia do Sertão Pernambucano for their technical assistance.

Author Contributions. MJMG and CAM conceived the study. MJMG, LRSA and FAR conducted data collection. IEAS performed statistical analyses. MJMG wrote the article.

Funding Information. This research received no specific grant from any funding agency, commercial or not-for-profit sectors.

Conflicts of Interest. All authors declare no conflicts of interest.

Data availability. The authors confirm that the data supporting the findings of this study are available within the article and/or its supplementary materials. If additional data is required, is available from the corresponding author, [MJMG], upon reasonable request.

Supplementary Materials. To view supplementary material for this article, please visit http://dx.doi.org/10.1017/exp.2020.27.

\section{References}

Dabove, P., \& Pietra, V. (2019). Towards high accuracy GNSS real-time positioning with smartphones. Advances in Space Research, 63, 94-102. doi:https://doi.org.10.1016/j.asr.2018.08.025.

Gonçalves, D. A. R., \& Borges, R. M. A. (2016). Utilização de aplicativos móveis no ensino da Topografia. Evidência, 12, 147-158.

Hwang, J., Yun, H., Suh, Y., Cho, J., \& Lee, D. (2012). Development of an RTK-GPS positioning application with an improved position error model for smartphones. Sensors, 12, 12988-13001. doi:https://doi.org/10.3390/s121012988. 
Machado, T. M., \& Molin, J. P. (2011). Ensaios estáticos e cinemáticos de receptores de GPS. Revista Brasileira de Engenharia Agrícola e Ambiental, 15, 981-988. doi:https://doi.org/10.1590/S1415-43662011000900015.

Moreira, G. L., Lemos, O. L., Rocha, L. S., \& Santos, K. C. O. (2014). Análise comparativa entre receptores GNSS no mapeamento topográfico e padrão de exatidão cartográfica. Enciclopédia Biosfera, 10, 214-223.

Yoon, D., Kee, C., Seo, J., \& Park, B. (2016). Position accuracy improvement by implementing the DGNSS-CP algorithm in smartphones. Sensors, 16, 910-926. doi:https://doi.org/10.3390/s16060910.

Cite this article: Guimarães MJM, Da Silva Araújo LR, Mogami CA, Rezende FDA, Santos IEDA (2020). Use of navigation GPSs in small topographical surveying Experimental Results, 1, e19, 1-6. https://doi.org/10.1017/exp.2020.27 


\section{Peer Reviews}

\section{Reviewing editor: Dr. Aurélie Shapiro}

World Wide Fund For Nature, Reinhardtstraße 18, Berlin, Germany, 10117

This article has been accepted because it is deemed to be scientifically sound, has the correct controls, has appropriate methodology and is statistically valid, and met required revisions.

\section{doi:10.1017/exp.2020.27.pr1}

\section{Review 1: Use of navigation GPSs in small topographical surveying}

Reviewer: Anderson Santos da Silva

Universidade Federal Rural de Pernambuco, Agronomia

Date of review: 26 May 2020

Published online:

(C) The Author(s), 2020. Published by Cambridge University Press This is an Open Access article, distributed under the terms of the Creative Commons Attribution licence (http://creativecommons.org/licenses/by/4.0/), which permits unrestricted re-use, distribution, and reproduction in any medium, provided the original work is properly cited.

Conflict of interest statement. The reviewer declares that there is no conflict of interest with the evaluated work.

Comments to the Author: The evaluated work is well written, detailed and succinct in what was proposed in the general objective, directly corroborating the results presented and discussed later with relevant references from the literature.

\section{Score Card}

Presentation

5.0

Is the article written in clear and proper English? (30\%)

Is the data presented in the most useful manner? (40\%)

Does the paper cite relevant and related articles appropriately? (30\%)

Context

Does the abstract correctly embody the content of the article? (25\%)

Does the introduction give appropriate context? (25\%)

Is the objective of the experiment clearly defined? (25\%)

Analysis

Are the limitations of the experiment as well as the contributions of the 


\section{Review 2: Use of navigation GPSs in small topographical surveying}

Reviewer: Dr. Jhon Lennon Bezerra da Silva (iD

UFRPE, Agricultural engineering, Recife, 141, Brazil, 52171-900

Date of review: 08 June 2020

Published online:

(C) The Author(s), 2020. Published by Cambridge University Press This is an Open Access article, distributed under the terms of the Creative Commons Attribution licence (http://creativecommons.org/licenses/by/4.0/), which permits unrestricted re-use, distribution, and reproduction in any medium, provided the original work is properly cited.

Conflict of interest statement. "Reviewer declares none".

Comments to the Author: The manuscript briefly addresses topographic information from geolocation data with navigation receivers and Smartphone. When they came out to the satisfaction of the present study new acquisition means information given need for data. Thus, it is worthwhile to continue the research for the improvement of technical characteristics and greater precision in the acquisition of data by these means of information.

\section{Score Card}

Presentation

Is the article written in clear and proper English? (30\%)

Is the data presented in the most useful manner? (40\%)

Does the paper cite relevant and related articles appropriately? (30\%)

Context

Does the title suitably represent the article? (25\%)

Does the abstract correctly embody the content of the article? (25\%)

Does the introduction give appropriate context? (25\%)

Is the objective of the experiment clearly defined? (25\%)

Analysis

Does the discussion adequately interpret the results presented? (40\%)

Is the conclusion consistent with the results and discussion? (40\%)

Are the limitations of the experiment as well as the contributions of the experiment clearly outlined? $(20 \%)$ 